\title{
A vida em cor de rosa: o romance sentimental e a difadura militar no Brasil
}

\section{RESUMO}

Este trabalho objetiva realizar uma reflexão sobre as interrelações entre a literatura de massa, em especial, os romances sentimentais e os valores morais e éticos estabelecidos pela ditadura militar no Brasil, durante o regime de exceção de 1964. A pesquisa parte do pressuposto de que a leitura é uma prática social, historicamente situada, que tanto constrói novas representações sobre o social como repercute visões consolidadas pela ordem dominante. Este é o caso dos romances sentimentais de Corin Tellado que, vendidos a preços populares, em meados dos anos 1960, em bancas de revista, foram uma grande aposta do regime na repercussão de certos valores, que na óptica das classes dirigentes, eram considerados condizentes com a nova ordem social.

\section{PALAVRAS- CHAVE}

Romances sentimentais

Valores morais

Ditadura militar

The life in rose color: the sentimental romance and the military dictatorship in Brazil

\section{ABSTRACT}

This essay has the intention to make a reflection on the mass literature, in special, the sentimental romances and the moral and ethical values established by the military dictatorship in Brazil, during the regimen of exception of 1964. The research is based on the idea that the reading is a social practical, historically situated that as much constructs new representations on the social as reverberates perspectives consolidated for the dominant order. This is the case of the sentimental romances of Corin Tellado, that sold in popular prices, in middle of years 1960, at magazine board, had been a great bets of the regimen in the repercussion of certain values, that in the optics of the leading classrooms, were considered correct with the new social order.

\section{KEYWORDS}

Sentimental romances

Moral values

Military dictatorship.

\section{Roberta Manuela Barros de Andrade}

Professora dos Cursos de Ciências Sociais, História, Geografia e Serviço Social da UECE/CE/BR

manubarros@secrel.com.br

\section{Erotilde Honório Silva}

Professora do Curso de Comunicacão Social da UNIFOR/CE/BR eroh@unifor.br

$\mathrm{Na}$ atualidade, uma das grandes questões que movem os estudos sobre a comunicação mediada tecnologicamente diz respeito ao desvendamento de suas relações com períodos históricos claramente importantes para a política brasileira. Dentre esses períodos de destaque, ressalta-se, neste trabalho, o ciclo que abarcou o Golpe Militar de 64. Neste contexto, a academia tem procurado, após a abertura política, em meados dos anos oitenta, tratar, com múltiplos vieses de análises, as interrelações entre bens produzidos na cultura de massa e este período de exceção. Entrementes, tem-se deixado sistematicamente em aberto reflexões que abranjam um segmento específico desta cultura de massa: a literatura popular, em especial, um de seus gêneros, que se convencionou chamar de romances sentimentais ou que, na nomenclatura francesa, são conhecidos como romances "cor de rosa".

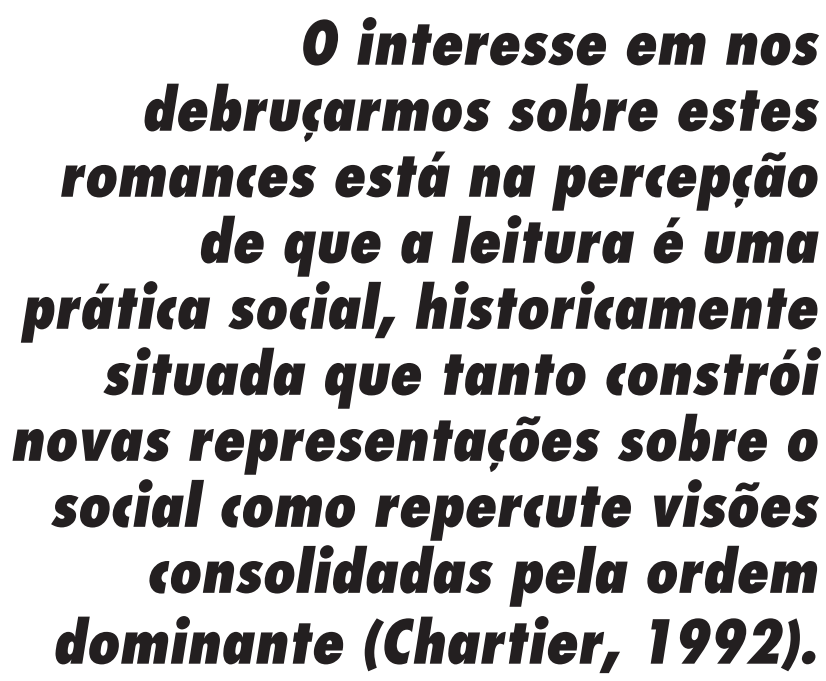


Este é o caso dos romances sentimentais de Corin Tellado que, vendidos a preços populares, em meados dos anos 1960, em bancas de revista, foram uma grande aposta do Regime na repercussão de certos valores, que na óptica das classes dirigentes, eram considerados condizentes com a nova ordem social. Esta nova ordem social requeria uma mediação que atingisse às classes populares, orientando a sua forma de pensar, agir e estar no mundo. Neste quesito, os romances sentimentais, pela sua estrutura narrativa, foram os porta-vozes, de certas representações sociais que se adequavam aos ditames das elites no poder.

Um romance sentimental é, antes de tudo, uma obra de ficção cuja temática trata de sentimentos e paixões. Trata-se, pois, de histórias de amor que concentram sua atenção sobre os estados emocionais e os conflitos internos das personagens muito mais do que sobre as ações externas (Samonà, 1980). Este novo gênero, surgido, na Europa, em fins do século XIX, derivado dos romances folhetins, se coloca como um dos carros-chefe da literatura de massa ou popular. Este produto, típico da indústria cultural, pretendendo atender a um novo público leitor - o feminino - tanto do universo burguês como do popular, adaptou os modelos da alta literatura às exigências de padronização e estereotipização da sociedade de consumo.

No Brasil, a entrada do romance sentimental se dá no mesmo período, em fins do século XIX, com o movimento romântico. Nas primeiras décadas do século XX até seus meados, eram vendidos, para as moças da classe média, em livrarias, por intermédio de coleções, cujo maior expoente, foi, com certeza, a Coleção Biblioteca das Moças (Cunha, 1999; Andrade; Silva, 2008; 2009). Este gênero encontra sua versão para as classes populares, nos romances de Corin Tellado, vendidos em banca de revistas, país afora.

Entre os anos de 1965 e 1975, período de endurecimento do Regime, que encontra seu ápice no AI-5, enquanto a censura modifica estruturalmente a produção dos noticiosos e as telenovelas começam a se instaurar como gênero ficcional soberano, as mulheres das classes populares consomem, pela primeira vez, uma literatura sentimental, essencialmente destinada a elas, encontrada em bancas de revista. Essa literatura, entre meados dos anos 1960 até fins dos anos 1970, encontra, no Brasil, seu maior sucesso editorial nas Coleções Trevo, Carícia, Amor, escritas pela espanhola Corin Tellado, que alcançou uma estrondosa popularidade em seu país de origem, durante o franquismo, expressão que se refere à ditadura militar de Francisco Franco, que dominou a Espanha de 1939 a 1975, período de sua morte.

Corin Tellado, pseudônimo da espanhola Maria Del Socorro Amália Tellado López, está entre as autoras de romance cor de rosa mais famosas do século XX. Tellado teve seu primeiro livro editado em 1946, na Espanha, se tornando rapidamente sucesso editorial em seu país de origem. Em 1962, com sua popularidade assegurada na Espanha, assina contrato com a editora Bruguera, que abre uma filial no Rio de Janeiro, e assume a tradução das obras de Tellado para o público brasileiro, ao mesmo tempo em que exporta seus livros para a Argentina, o México, o Chile, a Venezuela, a Colômbia, recebendo também vultosos investimentos publicitários.

Em 1962, a UNESCO declara que ela é a autora mais lida na Espanha, atrás apenas da Bíblia e de Cervantes. Seu esquema de produção permitia que escrevesse uma nova obra a cada cinco dias, perfazendo ao todo mais de 5.000 títulos, em 50 anos de carreira, englobando ainda roteiros adaptados para a TV e o cinema. Na América Latina, num período de dez anos, foram publicados mais de 70 títulos de sua Coleção. No Brasil, tal como em seu país de origem, os livros eram vendidos em formato de livro de bolso, assim chamado pelo seu tamanho menor que o usual $(15 \mathrm{~cm} \times 10,5 \mathrm{~cm})$, o que facilitava a sua compra e manuseio pelas classes populares.

Assim, a editora Bruguera objetivava garantir vultosas vendas e para esse fim investia no uso de papel jornal na produção dos livros de Corin Tellado, deixando o chamariz para as capas feitas em cores fortes sobre papel brilhante. Para adaptar à tipografia aos hábitos escassos de leitura das classes populares, as letras dos romances eram de tamanhos garrafais e as frases se caracterizavam pelo estilo curto e telegráfico, bem ao estilo dos folhetins do século anterior. Essas estratégias chamavam a atenção das jovens leitoras, em meio a outras opções frequentes nas bancas, como jornais e revistas daquele período. $\mathrm{O}$ formato que cabia na bolsa, facilitava a leitura, uma vez que garantia o seu consumo em qualquer lugar, tanto em transportes públicos como em salas de espera de escritório e hospitais e em intervalos de trabalho. A portabilidade foi, com certeza, uma das razões do seu êxito, aliada a uma estrutura narrativa simples, com personagens estereotipadas, que representavam jargões que já circulavam no meio social e eram evidenciados nas histórias.

São as coleções desta autora, publicadas no Brasil pela editora Bruguera, o objeto de reflexão deste trabalho. Tal como em seu país de origem, 
acreditamos que estes

romances contribuíram para cristalizar visões de mundo e modelar condutas a partir dos usos de um certo imaginário romántico que foi apropriado pelas elites brasileiras para a consolidação de um sistema autoritário.

Este sistema autoritário criou uma ideologia, amplamente difundida nos meios de comunicação, que propiciava a legitimação social necessária para a sedimentação de uma nova sociedade de consumo, baseada na aquisição de bens de luxo e/ou supérfluos.

Esta inserção das classes populares na sociedade de consumo era orientada não só pela publicidade, mas também, pela incorporação dos hábitos e comportamentos protagonizados pela ficção de Corin Tellado. As tramas desta autora apresentavam um universo no qual as idas aos clubes, a frequência a restaurantes, a aquisição de carros e lambretas, as viagens de férias estavam incorporadas aos hábitos de vida de seus personagens. Tais hábitos de consumo compactuavam com a aura de modernização que envolvia o Brasil neste período.

Estes romances, apesar de não fazerem referências a eventos políticos específicos nem a símbolos nacionais, enfocavam visões sobre decência, honestidade, força de caráter, que embutidas em relações desiguais de gênero, auxiliaram na preservação do status quo daquele período. A escolha pela análise dos romances sentimentais de Corin Tellado, como representantes de valores necessários à nova ordem política, está baseada em duas premissas. A primeira diz respeito à sua popularidade entre as mulheres das classes populares, o que garante a sua legitimidade como objeto de estudo, uma vez que, seu sucesso editorial atingiu a um segmento da sociedade brasileira ainda pouco estudado pela academia; a segunda deve-se ao uso da ficção transmitir atitudes e valores sociais que o poder estabelecido percebia como necessários à consolidação do regime ditatorial no País.

Neste sentido, as críticas correntes de que neste tipo de literatura o social, o político e o econômico estariam ausentes, de que as personagens existem num vácuo, parece carecer de sentido. $\mathrm{O}$ ambiente, as atitudes e comportamentos das personagens inseridos nestes romances nos indicam a presença de um conjunto de pressupostos que, no período histórico em questão, refletiram os valores dominantes das elites militares/ burguesas que governavam o país.

\section{A característica mais forte apresentada nesta escritora era a descrição dos hábifos e comporfamentos de uma classe média urbana, que se adequava aos sonhos de consumo inseridos nos sistemas midiáticos e que sustentavam a política econômica que culminaria no Milagre Econômico Brasileiro.}

Deste modo, vendidas a baixo custo em bancas de jornal, suas histórias visavam, prioritariamente, a um público leitor feminino em processo de urbanização. Este impulso para a "modernização" dera seus primeiros passos na era Kubitschek, no seu projeto desenvolvimentista ousado de realizar 50 anos de progresso em 5 anos de ação política. Esse ideal desenvolvimentista foi consolidado num conjunto de objetivos a serem concretizados em vários setores da economia. A principal mudança de seu governo nos trâmites históricos foi a construção de Brasília e a transferência da capital federal para o novo território (Singer, 1981). Neste sentido, a ideia do desenvolvimento estava baseada na vida urbana industrializada. Segundo Figueiredo (1998), à cidade e à indústria cabia um papel civilizador. Esse papel aparecia em vários anúncios da época como o da Eletrobrás que preconizava "energia para as cidades, desenvolvimento para o interior".

As metas eram grandiosas e, em sua maioria, alcançaram resultados considerados positivos. O crescimento das indústrias de base, fundamentais ao processo de industrialização, foi de praticamente 100\% no quinquênio 1956-1961. O avanço econômico aliado 
a práticas democráticas, apesar do aumento da inflação e das consequências daí oriundas, deram ao povo a sensação de que sair do atraso econômico era possível. A sociedade adquirira uma expectativa de modernização, ideal cuja realização dependia da chegada do progresso que se alicerçaria na transformação de uma economia agrária para uma etapa de crescimento industrial e urbano (Figueiredo, 1998; Singer, 1981).

Neste contexto, as classes menos favorecidas já podiam gozar do privilégio de usufruir das incitações de desejos da nova sociedade de consumo. No entanto, esta demanda esteve em perigo, após Kubitschek, com o governo Goulart e o medo das elites da ascensão do regime comunista no País. No campo da política, a "crise" foi solucionada pela instauração do Regime de Exceção de 1964. O golpe militar de 1964 garante, assim, a uma emergente classe média a continuidade de um novo status social e apregoa para as classes populares a possibilidade de entrada na sociedade de consumo. Mas, apesar dos ideais modernistas, o Brasil vivia um processo desordenado de urbanização.

Grande parte da população ainda era analfabeta ou semianalfabeta, morava em bairros de periferia, trabalhava em locais distantes desses bairros. A escola, quando havia, era precária e o atendimento à saúde também de difícil acesso. Os equipamentos culturais disponibilizados pelo Estado eram muito escassos e os existentes mal chegavam para a fruição das elites econômicas. $\mathrm{Na}$ política, imperava as oligarquias que realizavam alianças entre si e entre o poder religioso. Mas, enquanto esse cenário se formava, a juventude mais seleta socialmente ouvia os acordes da bossa nova enquanto as classes populares, pela primeira vez, se deliciavam com a leitura de Corin Tellado.

\section{Amor Romântico, ideologia e controle social}

Os romances de Corin Tellado representam uma percepção do amor, construída, datada e ordenada no que a literatura especializada chamou de amor romântico. O ponto central de sua obra, tal como em seus congêneres, conjuga sexo, amor e casamento, propondo um amor recíproco e indissolúvel, cuja finalidade última é a felicidade (Áries, 1987). Em Corin Tellado, ao mesmo tempo em que o amor romântico abarca a sexualidade, ele também rompe com ela, pois, ali, o amor sublime deve predominar sobre o ardor sexual. Neste sentido, dá-se um novo significado para a "virtude", que passa a compreender qualidades do caráter de uma pessoa, o que a distingue das demais.

\section{0 romance ideal, em Tellado, assim como a emoç̃̃o ideal estão circunscritos a noções que aliam o amor à paixão, legitimados por sentimentos de posse.}

Assim como a proposta de unidade entre amor e sexualidade foi fundamental para o amor romântico (Lázaro, 1996) - proposta esta que faz com que o casal busque um no outro tanto satisfação amorosa quanto sexual —, também foram as ideias de reciprocidade e de exclusividade, típicas da estrutura narrativa de Corin Tellado. O amor devia se realizar completa e simultaneamente com reciprocidade e era a unidade de sentimentos que dava sentido e sustentação ao relacionamento. A relação amorosa era percebida e vivida como um investimento emocional a dois, mas não "quaisquer dois", e sim dois indivíduos específicos, exclusivos, que com suas próprias "virtudes" despertavam um no outro o amor (Giddens, 1993.).

Mas, se a escolha amorosa romântica deveria ser realizada livremente e em função do compartilhamento de amor e desejo, sendo a reciprocidade de sentimentos que dava sentido e sustentação ao relacionamento, é de se supor que este estado pudesse não perdurar para sempre, que ele se esgotasse e deixasse os indivíduos livres para mais uma expedição conjunta e extensa. Assim, para tentar neutralizar um certo direcionamento que poderia ousar romper o tecido social das relações dominantes, o amor romântico é domesticado. Ao ser levado para dentro do casamento, o amor romântico é apaziguado porque colocado como alicerce para um casamento eterno, consolidando, desta feita, a coesão da família (Vainfas, 1986). Assim, a junção de sexualidade e amor no casamento torna-se fundamento da relação e modo de controle das vidas privadas, perdendo, assim, seu caráter transgressor e inovador.

Destarte, qualquer referência à revolução sexual que ocorria em determinados países ocidentais, neste mesmo período, era barrada. Neste contexto, os romances tinham a função de denunciar o desregramento sexual oriundos de certos países europeus e norte americanos, cuja liberalidade apontava para segmentos da elite em franco declínio moral. Num contexto de 
censura e restrições que caracterizou a ditadura militar brasileira, a autora escrevia histórias de amor nas quais obrigatoriamente a heroína era descrita como uma atraente mulher que precisava de abrigo-proteção de um parceiro que a sustentasse e mantivesse dentro da época e da moral vigente. Esta caracterização obedecia, desta forma, tanto aos ditames morais da ditadura militar espanhola quando aos da brasileira, sendo úteis aos governos totalitários desses países.

Durante a ditadura, a noção de amor romântico de Tellado agradava aos dois regimes de exceção por duas razões. Os censores do poder não permitiam a publicação de material que fizesse referência a comportamentos sexuais. Os encontros casuais ou de natureza mais desinibida eram interditados pela censura e pelos editores porque poderiam ser percebidos como contrários à moral e aos bons costumes. A narrativa tinha, assim, seu desfecho com o casamento católico. O controle governamental por todas as formas de publicação, incluindo histórias de amor, significava a impossibilidade de aceite de relações fora do paradigma do amor como atração heterosexual que culminava no casamento como resolução do enredo. Assim, não existia final sem o amor romântico e nenhum amor romântico poderia existir sem a virgindade, virgindade requerida como sacrifício, sacrifício que com certeza e cedo seria recompensado pelo casamento.

A autora encontrou e repetiu uma formula extremamente eficaz: as mulheres só têm valor quando resistem ao sexo fora do casamento e nenhum homem respeitará uma mulher que se entrega antes do matrimônio, sacramentando, desta feita, as rígidas regras invisíveis do espaço doméstico e suas funções no social. Assim,

\section{os romances de Corin Tellado fomentavam, no imaginário de suas jovens leiforas, a resignação, a preservação da virgindade e a abnegação frente à perfídia masculina.}

Entre corredores que cheiravam a odor de repolho cozido, de correntes atadas às máquinas de costura e às missas diárias, as classes populares sonhavam com seu príncipe encantado.

Nas tramas, em geral, as heroínas compartilham uma dramática experiência de sofrimento e de virtude imaculada. Em geral, como é usual nestes livros, o sofrimento vem de um isolamento do social (no caso de serem órfãs), de empobrecimento econômico ou de maus tratos de parentes desalmados. A virtude é usualmente apresentada como um modo de submissão aos ditames morais do catolicismo, em especial, na forma da virgindade. A combinação de sofrimento e virtude é recompensada ao final da trama pelo êxito no casamento. O homem não só complementa perfeitamente a mulher, mas também, é a solução ideal para seus problemas. Os romances de Corin Tellado frequentemente têm descrições de beijos e abraços apaixonados, mas apesar de conter personagens femininas que sugerem um sexo pré-marital com seus parceiros, efetivamente o ato não se concretiza até o casamento, sendo condição para a sua realização.

Este imperativo da virgindade chega a construir uma moralidade que legitima o uso da violência física para constranger o outro no ato sexual. Em Primeira Noite de Casados, Maud pensa ter sido estuprada, após um desmaio resultante de uma briga, gerada por ciúmes, na qual Marx, seu primeiro amor, fora de si, a força com beijos a aceitar suas ousadias. Ao se recuperar do desmaio, Maud acaba aceitando sua proposta de casamento porque, segundo Marx, nenhum homem honesto quererá para esposa uma mulher "marcada" por outro, independente desta ter ou não colaborado para o ato em si.

Desta feita, o governo vigiava a literatura de massa e esta funcionava como um mecanismo eficiente para conduzir e controlar o processo de produção de ideias no País. No Brasil, a mídia trabalhava em conjunto com o ideário difundido por tal literatura, promovendo certos tipos de imagens cuja fórmula agregava valor ao engajamento dos autores e editores a esta ideologia que propagava a continuidade das desigualdades nas relações de gênero. Neste princípio de intertextualidade, as revistas destinadas ao público feminino ilustravam como casais famosos que não selecionavam parceiros conforme as normas do amor idealizado eram objeto de críticas, olhados com desconfiança, como eram os casos das artistas de teatro, de rádio e da TV. No enredo, as mulheres eram sempre alguns anos mais jovens que seus parceiros e com padrão econômico inferior ao dos seus companheiros. O homem tinha que ser forte, ter nível econômico e exibir uma alta educação. Ele deveria repassar preceitos sociais à sua parceira, enfim, era o 
"cabeça" do casal.

Neste contexto, o amor romântico que passou a servir de alicerce para o casamento burguês, marcado pela ênfase no amor eterno, pela liberdade de escolha e pela exclusividade e reciprocidade dos parceiros, reproduzia uma ordem que confinava a mulher à esfera privada (Del Priori, 2006). Portanto, nestes romances, os papéis masculinos e femininos eram bem demarcados, vigiados e cumpridos à risca. No romance Carolina, se a heroína da história, iniciava a trama insatisfeita com o casamento, não era porque estava confinada ao aprisionamento da esfera privada, mas porque não havia aprendido a revelar seus verdadeiros sentimentos ao marido e ainda era incapaz de compreender os sentimentos deste em relação a si própria.

As promessas do amor romântico, assim, se definem pela satisfação sentimental, jamais pela mudança da ordem social. Esta idéia serviu essencialmente ao regime de exceção. Neste contexto, a felicidade iria re-energizar, fortalecer, o homem que se confrontava cotidianamente com as adversidades da vida laboral, pública, e que chegava em seu "lar" necessitando do amparo, da compreensão e do amor de sua esposa. (Lipovetsky, 2000). Assim, no amor romântico temos a criação do "lar" como um ambiente distinto do trabalho, onde, ao menos a princípio, o indivíduo poderia encontrar apoio emocional. Incentivadas a ocupar tal lugar na ordem social, as expectativas e sonhos das jovens leitores de transformações estavam vinculadas ao casamento, que significava o encontro com a felicidade.

Com o casamento, estava em jogo, para estas jovens mulheres da classe popular, a possibilidade de satisfação amorosa, de ter acesso a um novo estilo de vida e a uma mudança no rumo de seus destinos. Assim,

\section{os romances de Corin Tellado, ao mesmo fempo em que fornavam possíveis sonhos de intensidade emocional, colocavam esta mesma mulher, em sifuação de dependência do homem provedor, presa à esfera doméstica, destinada a cuidar dos filhos e da casa (Costa, 2005).}

Cabia, pois, à mulher, contribuir para a construção de um espaço privado acolhedor, protetor, que se contrapusesse à subjetividade, dificuldades e frustrações da vida cotidiana pública, a qual, ela não deveria fazer parte. Quando, em Carolina, a protagonista pensa em se separar do marido, devido a ciúmes infundados de ambas as partes (principal razão dos desentendimentos dos casais em Corin Tellado), e procura sua mãe, após uma discussão na qual foi estapeada, a mãe nega a possibilidade de separação, afirmando que o sofrimento fazia parte da vida das mulheres, e aconselhando-a a não ser tão provocadora dos instintos primitivos dos homens. Essa era, para Corin Tellado, a fórmula para o casamento burguês bem sucedido, a ser seguido pelas mulheres populares deste período.

\section{A ordem do coração e o conformismo social}

O prazer na leitura de Corin Tellado parece, assim, derivado da habilidade da narrativa em negociar e resolver as desigualdades de poder nas relações de gênero através do triunfo do matrimônio que supera toda e qualquer adversidade. (Radway, 1987). Segundo Mattelart (1982), nas histórias românticas esta "ordem do coração" invalida qualquer forma de luta contra as desigualdades sociais, apesar de sua existência ser admitida, porque difunde a ideia de que somente o amor ultrapassa barreiras. Não somente a solução é individual - nunca coletiva - mas está sempre ligada a um milagre. O amor passa a ser a explicação universal que resolve as contradições sociais, negando-as.

Neste sentido, a noção do amor romântico, se presta, ao controle e vigilância sobre as práticas consideradas inapropriadas pela ordem dominante vigente no Brasil. Este controle era exercido pelas famílias, pelos puritanos e moralistas com o objetivo de cercear as possibilidades de movimento ou mudança dos indivíduos, regular suas relações de intimidade, exigir deles autocontrole e impor restrições às satisfações sexuais e sentimentais. A obra de Corin Tellado parece revelar uma estrutura conformista, baseada no uso de certa estrutura melodramática, herdada do folhetim, que se centra na construção/ solução dos obstáculos que separam um par romântico heterossexual. Nesse sentido, o romance parece ser uma forma dramática cujo enredo sentimental sacrifica caracterizações por extravagantes incidentes, fazendo sensacionais apelos às emoções que terminam sempre em 
lições morais. As personagens, nessa óptica, são tomadas por suas emoções violentas, dentro das quais parece não haver lugar para a reflexão, para o distanciamento intelectual ou para a relativização.

Estes romances expõem práticas morais particulares que distanciam seu público alvo dos movimentos de liberação sexual tolerados nas sociedades democráticas. Ao contrário, tais enredos propagam ideais de romance e amor que reforçavam certo comportamento sexual que compactuava com interesses políticos e religiosos, em especial, os da Igreja Católica, aliada tanto do franquismo quanto do militarismo brasileiro, pelo menos, em seus primeiros anos, continuando a ser uma referência para a sociedade brasileira, durante todo o período de exceção pelo qual o país passou.

A leitora decente deveria encontrar uma forma de negociar suas concepções de amor, sexo, casamento com uma só pessoa, que deveria ser do sexo masculino, de preferência, honesto, trabalhador e cumpridor de seus deveres sociais. Entre esses deveres, cumprir o que manda a lei, parecia ser o maior deles, o que servia, de forma, seminal aos ditames do regime. Se não fossem partidários desse comportamento, eram tratados como licenciosos, e rapidamente, passavam a pertencer ao grupo de vilões da trama. Assim, as pessoas decentes deveriam compreender os limites dessa fronteira, utilizando-se das armas de um código moral hipócrita que as governava. Quem não estava dentro dessas fronteiras, era denominada de divorciada, mãe solteira e/ ou prostituta e jamais apareciam nestes romances, nem sequer em posição secundária.

Assim, os romances cor de rosa contribuíam para o governo militar reconstruindo o Brasil. Os textos ficcionais estavam ali para refletir as virtudes da nova classe média, e para preservar estas virtudes. Suas experiências deveriam ser adaptadas a partir dos moldes estabelecidos pelo regime. Neste contexto, os romances alcançaram seus objetivos. Os finais felizes, entre pessoas de bem belas e bem sucedidas, serviam para mascarar a miséria do país, para aqueles que não estavam sendo beneficiados pelo milagre econômico. Ao mesmo tempo em que a energia sexual dos indivíduos era sublimada, o controle ideológico e ético da Igreja e do Estado estava preservado.

\section{REFERÊNCIAS}

ARIĖS, Philippe. O amor no casamento. In: ARIÈS, Philippe; BÉJIN, André. (Orgs). Sexualidades Ocidentais.
São Paulo: Brasiliense, 1987.

ANDRADE, Roberta Manuela Barros de; SILVA, Erotilde Honório. Os romances sentimentais do Século XX no Brasil. XXXI Congresso Brasileiro de Ciências da Comunicação, Natal, 2008.

ANDRADE, Roberta Manuela Barros de; SILVA, CHARTIER, Roger. Textos, impressões, leituras. In: HUNT, Lynn. A nova história cultural. Rio de Janeiro: Martins Fontes, 1992.

COSTA, Sérgio. Amores fáceis. Novos estudos - CEBRAP. São Paulo, n.73, p. 111-124, 2005.

CUNHA, Maria Teresa Santos. Armadilhas da sedução: os romances de M. Delly. Belo Horizonte, Autêntica, 1999.

DEL PRIORI, Mary. História do Amor no Brasil. São Paulo: Contexto, 2006.

FIGUEIREDO, Anna Cristina Morais. Liberdade é uma calça velha e desbotada. São Paulo: Hucitec, 1998.

GIDDENS, Anthony. A transformação da Intimidade. Sexualidade, amor e erotismo nas sociedades modernas. São Paulo: UNESP, 1993.

HONÓRIO, Erotilde. A atração sexual nos romances sentimentais (1940-1960): Amor e Paixão em Elinor Glyn. In: XXXII Congresso Brasileiro de Ciências da Comunicação. Universidade Positivo, Paraná, 2009.

LÁZARO, André. Amor: Do mito ao mercado. Petrópolis: Vozes, 1996,

LIPOVETSKY, Gilles. A Terceira Mulher: Permanência e Revolução do Feminino. São Paulo: Companhia das Letras, 2000.

MATTELART, Armand. Women and the culture industrie, Media Culture and Society. Vol. 4. Harvard: Harvard Press, 1982.

RADWAY, Janice. Reading the romance: women, patriarchy and popular literature. London, Verso, 1987.

SAMONÀ, Carmelo. Los códigos de la novela 
sentimental. Historia y crítica de la literatura española. Barcelona: Crítica, 1980.

SINGER, Paul. Interpretação do Brasil: uma experiência histórica de desenvolvimento. In: BÓRIS, Fausto, (org).
O Brasil Republicano III: economia e cultura (1930-1964). São Paulo: Difel, 1981.

VAINFAS, Ronaldo. Casamento, amor e desejo no ocidente cristão. São Paulo: Ática, 1986. 